\title{
Minimally invasive surgery for perihilar cholangiocarcinoma: a systematic review
}

\author{
L. C. Franken ${ }^{1}$ (D) M. J. van der Poel ${ }^{1} \cdot$ A. E. J. Latenstein ${ }^{1} \cdot$ M. J. Zwart ${ }^{1} \cdot$ E. Roos ${ }^{1} \cdot$ O. R. Busch ${ }^{1} \cdot$ M. G. Besselink $^{1}$. \\ T. M. van Gulik ${ }^{1}$
}

Received: 3 January 2019 / Accepted: 13 April 2019 / Published online: 2 May 2019

(c) The Author(s) 2019

\begin{abstract}
Minimally invasive surgery (MIS) is quickly becoming mainstream in hepato-pancreato-biliary surgery because of presumed advantages. Surgery for perihilar cholangiocarcinoma (PHC) is highly demanding which may hamper the feasibility and safety of MIS in this setting. This study aimed to systematically review the existing literature on MIS for PHC. A systematic literature review was performed according to the PRISMA statement. The PubMed and EMBASE databases were searched and all studies describing MIS in patients with PHC were included. Data extraction and risk of bias were assessed by two independent researchers. Overall, 21 studies reporting on a total of 142 MIS procedures for PHC were included. These included 82 laparoscopic, 59 robot-assisted and 1 hybrid procedure(s). Risk of bias was deemed substantial. Pooled conversion rate was $7 / 142(4.9 \%)$, pooled morbidity $30 / 126(23.8 \%)$, and pooled mortality rate $4 / 126(3.2 \%)$. The only comparative study, comparing 10 robot-assisted procedures to 32 open procedures, reported a significant increased operative time and higher morbidity rate with MIS. The available evidence on MIS for PHC is limited and generally of poor quality. This systematic review shows that the implementation of MIS for patients with PHC is still in its infancy.
\end{abstract}

Keywords Perihilar cholangiocarcinoma $\cdot$ Minimally invasive surgery $\cdot$ Systematic review

\section{Introduction}

Perihilar cholangiocarcinoma (PHC) is an uncommon type of cancer with a bad prognosis. Surgical resection, usually entailing hilar resection with extended hepatectomy, is the only potentially curative treatment. These procedures are considered highly challenging due to the tumors' proximity to the portal vein and hepatic artery [1]. Severe morbidity (Clavien-Dindo $\geq \mathrm{III}$ ) can rise up to $27.5-54 \%$ and mortality is high with rates of 1.4-18\% [2-6]. The efficiency of surgical treatment of $\mathrm{PHC}$ has progressed in recent years with the surgical strategy changing from limited bile duct resections

L.C. Franken and M.J. van der Poel shared first authorship.

T. M. van Gulik

t.m.vangulik@amc.nl

L. C. Franken

1.c.franken@amc.nl

1 Department of Surgery, Cancer Center Amsterdam, Amsterdam, UMC, University of Amsterdam, Amsterdam, The Netherlands to resections including hepatectomy at the end of the twentieth century $[3,7]$. This aggressive approach led to increased rates of $R 0$ resections and 5-year survival [7, 8]. However, post-operative morbidity and mortality remain an issue.

Minimally invasive surgery (MIS) is increasingly being implemented in all types of hepato-pancreato-biliary resections including distal pancreatectomy and hepatectomy [9-11]. Promising results, inherent to a minimally invasive approach, such as faster functional recovery, less intraoperative blood loss, and less post-operative complications are frequently reported [10]. In liver surgery, laparoscopic and robot-assisted procedures have been increasingly used and show improved post-operative outcomes without compromising long-term oncological outcomes [11-13]. The extremely challenging nature of the procedure, the technical skills required, and the fear of oncological inefficiency have so far limited the adoption of MIS for PHC. Nevertheless, outcome of MIS for PHC has been reported [14]. A systematic review on MIS in patients with PHC is lacking. 


\section{Objective}

This systematic review aims to appraise the current literature on implementation and outcome of MIS for the treatment of PHC.

\section{Methods}

The protocol of this study was registered in PROSPERO under number CRD42017074398. This systematic review is created in accordance with the Preferred Reporting Items for Systematic Review and Meta-Analyses (PRISMA) statement. We aimed to identify studies reporting on MIS in patients with PHC (i.e., Klatskin tumor). All study types in which a total laparoscopic (including hand assisted), robotassisted and/or hybrid approach was described were eligible for inclusion. Studies without original data (e.g., reviews) and studies published in languages other than English were excluded. In case multiple eligible studies were published by the same group, the one with the highest number of cases was selected. To identify relevant studies, a search was conducted in PubMed and EMBASE on September 5th 2017. The search strategy was checked and approved by a clinical librarian. We used a combination of the following $\mathrm{MeSH}$ terms, keywords and search terms:

("Laparoscopy"[Mesh] OR laparoscop* [tiab] OR "HandAssisted Laparoscopy"[Mesh] OR Hand Assisted Laparoscopy [tiab] OR "Robotic Surgical Procedures"[Mesh] OR robot* [tiab] OR "Minimally Invasive Surgical Procedures"[Mesh] OR Minimally Invasive OR hybrid [tiab]) AND ("Cholangiocarcinoma"[Mesh] OR cholangiocarcinoma* [tiab] OR Klatskin[tiab] OR "Bile Duct Neoplasms"[Mesh] OR Bile Duct cancer*[tiab] OR Bile Duct neoplasm*[tiab]).

\section{Data extraction and outcome measures}

Two independent researchers (MJvdP and AL) screened abstracts and full texts for eligibility based on the inclusion and exclusion criteria. Any discrepancies were resolved by a third reviewer (MZ). Data were extracted using an extraction form and comprised the following variables: article details (author, title, demographics, year of publication, study type), amount of patients, preoperative characteristics (gender, age, type of Klatskin tumor according to the Bismuth-Corlette classification, symptoms, radiologic features), operative specifics (type of operation, technique, operative time, blood loss, conversion), and post-operative outcomes (morbidity, mortality, hospital stay, resection margins, hospital costs, recurrence and disease-free survival).
Two researchers (MJvdP and LCF) assessed the individual risk of bias on study level using the Newcastle-Ottawa Scale for Cohort studies and the Joanna Briggs Institute (JBI) Critical Appraisal Tools for Case Series and Case Reports. Discrepancies were resolved in a consensus meeting. Results from the risk of bias assessments for case series and case report are displayed in separate figures. Overall, risk of bias across studies is evaluated by assessing the selection bias, detection bias, attrition bias, and reporting bias.

\section{Results}

\section{Study selection}

The initial search yielded 3939 studies. After removal of duplicates, a total of 3586 studies were screened for eligibility. This led to the screening of 111 full texts, which resulted in the inclusion of 21 studies [15-35]. Figure 1 displays the PRISMA flow diagram of study selection.

\section{Study characteristics}

The 21 eligible studies included one retrospective comparative study, 6 case series, 5 case reports, 7 video abstracts, and 2 abstracts of posters. All studies had a retrospective design and the first study was published in 2010. All study characteristics of included studies are listed in Table 1. The only comparative study conducted by Xu et al., compared 10 robot-assisted procedures to 32 open procedures in patients with PHC. The largest series contributing to this systematic review consists of 44 patients [33]. As shown in Table 1, there were 14 studies (including 82 patients) that reported an accurate follow-up of more than 90 days with a maximum follow-up of 60 months [15-21, 23-25, 28, 31, 34, 35]. Six studies (11 patients) reported no follow-up after discharge $[17,26,27,29,30,32]$. The follow-up period was unclear in one study (44 patients) [33].

\section{Critical appraisal}

The quality of the only comparative study [15] was assessed as poor on the Newcastle-Ottawa Scale, due to the lack of comparability and absence of controlling for confounders. Results of the Risk of Bias Assessment per study are displayed separately for case series and case reports in Figs. 2 and 3 , respectively. 

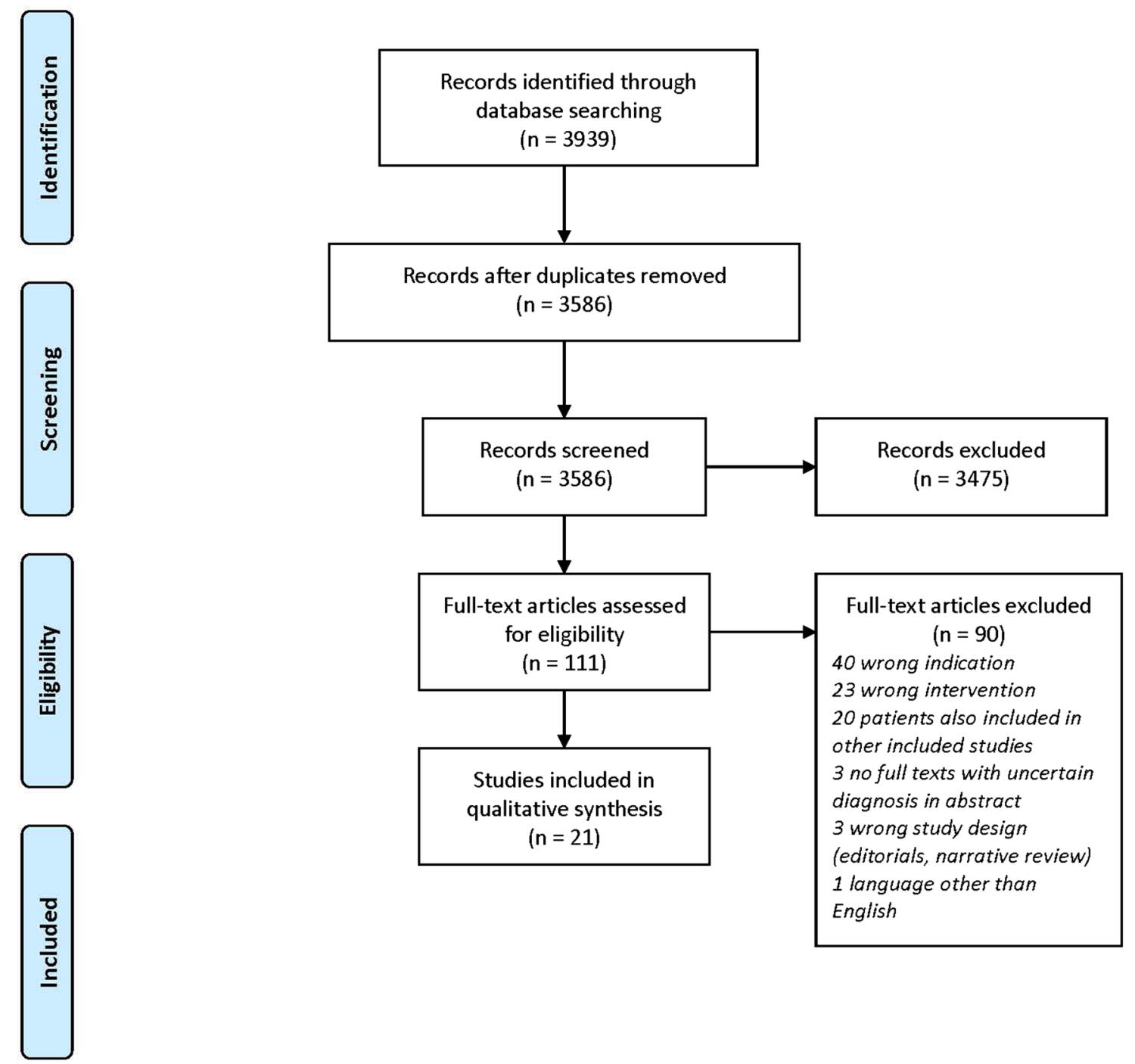

Fig. 1 A flowchart of included studies

\section{Risk of bias}

The majority of authors did not describe why they had subjected individual patients to minimally invasive procedures, causing a high risk of selection bias. None of the studies described that post-operative outcomes were assessed by an independent objective examiner. Also, a substantial proportion of the studies provided incomplete outcome data. These findings are highly suggestive for risk of detection and attrition bias. The inclusion of 11 case reports with no post-operative deaths and the lack of consecutive inclusion in case series suggest a publication bias.

\section{Patient and procedure characteristics}

A total of 142 patients undergoing minimally invasive procedures for PHC were identified. Among 15 studies reporting on gender of their population, there were 59 men (69\%) and 26 (31\%) women. Reported age of included patients ranged between 25 and 90 years, with a mean age of 61 years. The most frequently reported presenting symptom was jaundice. Thirteen studies described Bismuth-Corlette stage (BC) of their study population, including $29,32,12,6$, and 8 patients with type I, type II, type IIIa, type IIIb, and type IV tumors, respectively. Detailed patient demographics per study are listed in Table 1.

The 142 included procedures contained 82 laparoscopic, 59 robot-assisted, and 1 hybrid procedure(s). The first minimally invasive procedure for PHC was described by Chen et al. [16], performed in 2000. The da Vinci ${ }^{\circledR}$ Robotic Surgical System was used for the majority of robot-assisted procedures. External bile duct resection only was performed in 63 cases. Additionally, external bile duct resection was combined with a major hepatectomy in 35 patients (15 left 
Table 1 Study characteristics

\begin{tabular}{|c|c|c|c|c|c|c|c|}
\hline First author & Year & Country & Study type & Approach & No. of pts. & $\begin{array}{l}\text { Patient character- } \\
\text { istics }\end{array}$ & Reported FU (months) \\
\hline $\mathrm{Xu}$ et al. [15] & 2016 & China & Comparative study & Robotic & 10 vs. 32 & $\begin{array}{l}\text { MIS: } 8 \text { men, } 2 \\
\text { women, median } \\
54 \text { years, BC type } \\
\text { II (1), IIIa (4), IIIb } \\
(1), \text { IV(4) }\end{array}$ & $\operatorname{Max} 60$ \\
\hline Chen et al. [16] & 2013 & China & Case series & Laparoscopic & 36 & $\begin{array}{l}27 \text { men, } 9 \text { women, } \\
\text { mean } 66 \text { years } \\
(45-85), \text { BC type I } \\
(17), \text { II (19) }\end{array}$ & 4 pt LFU, 32 pt $>6$ \\
\hline Yu et al. [17] & 2011 & China & Case series & Laparoscopic & 14 & $\begin{array}{l}8 \text { men, } 6 \text { women, } \\
\text { mean } 55.7 \text { years } \\
(51-57), \text { imaging } \\
\text { BC type I (8), II } \\
(6) .\end{array}$ & $20(7-33)$ \\
\hline Li et al. [18] & 2017 & China & Case series & Laparoscopic & 9 & $\begin{array}{l}6 \text { men, } 3 \text { women, } \\
\text { median } 62.7 \text { years } \\
(50-74), \text { BC type I } \\
\text { (1), II (3), IIIb (2), } \\
\text { IV (3), no vascular } \\
\text { involvement }\end{array}$ & $17(6-42) 2 \mathrm{pt} \mathrm{LFU}$ \\
\hline Lee et al. [19] & 2015 & Korea & Case series & Laparoscopic & 5 & $\begin{array}{l}5 \text { men, median } \\
63 \text { years (43-76), } \\
\text { BC type I (1), II } \\
\text { (1), IIIa (1), IIIb } \\
\text { (2) }\end{array}$ & $8(5-9)$ \\
\hline Gumbs et al. [20] & 2013 & USA/Chile/France & Case series & Laparoscopic & 5 & $\begin{array}{l}\text { Mean } 73 \text { years } \\
\quad(66-79)\end{array}$ & $11(3-18)$ \\
\hline Quijano et al. [21] & 2016 & China & Case series & Robotic & 1 & - & 3 \\
\hline Yu et al. [22] & 2013 & China & Case report & Laparoscopic & 2 & $\begin{array}{l}2 \text { women, } \\
54+60 \text { years, } \\
\text { BC type I }\end{array}$ & 6-9 days \\
\hline $\begin{array}{l}\text { Puntambekar et al. } \\
\text { [23] }\end{array}$ & 2016 & India & Case report & Laparoscopic & 1 & $\begin{array}{l}\text { 25-Year-old man, } \\
\text { BC type II, no vas- } \\
\text { cular involvement }\end{array}$ & 6 \\
\hline Zhu et al. [24] & 2014 & China & Case report & Robotic & 1 & $\begin{array}{l}\text { 43-Year-old man, } \\
\text { BC type IIIa }\end{array}$ & 12 \\
\hline Machado et al. [35] & 2012 & Brazil & Case report & Laparoscopic & 1 & $\begin{array}{l}\text { 43-Year-old woman, } \\
\text { BC type IIIb }\end{array}$ & 18 \\
\hline Giulianotti et al. [25] & 2010 & USA & Case report & Robotic & 1 & $\begin{array}{l}\text { 66-Year-old man, } \\
\text { PVE }\end{array}$ & 8 \\
\hline Zhang et al. [26] & 2018 & China & Video abstract & Laparoscopic & 1 & $\begin{array}{l}\text { BC type IIIa, no vas- } \\
\text { cular involvement }\end{array}$ & 11 days \\
\hline Weaver et al. [27] & 2010 & USA & Video abstract & Laparoscopic & 3 & BC type IIIa & 10-14 days \\
\hline Efanov et al. [28] & 2015 & Russia & Video abstract & Robotic & 1 & $\begin{array}{l}\text { 65-Year-old man, } \\
\text { BC type II, CHA } \\
\text { replaced by and } \\
\text { RHA adhered to } \\
\text { tumor. }\end{array}$ & 5 \\
\hline Nakahira et al. [29] & 2015 & Japan & Video abstract & Laparoscopic & 3 & - & 19 days (16-23) \\
\hline Chen et al. [30] & 2017 & Taiwan & Video abstract & Hybrid & 1 & $\begin{array}{l}\text { BC type IV, 90-Year- } \\
\text { old woman, no } \\
\text { vascular involve- } \\
\text { ment }\end{array}$ & 9 days \\
\hline Machado et al. [31] & 2014 & Brazil & Video abstract & Laparoscopic & 1 & $\begin{array}{l}\text { 58-Year-old woman, } \\
\text { BC type IIIa }\end{array}$ & 16 \\
\hline Ji et al. [32] & 2011 & China & Video abstract & Robotic & 1 & 54-Year-old man & 12 days \\
\hline
\end{tabular}


Table 1 (continued)

\begin{tabular}{lllllll}
\hline First author & Year & Country & Study type & Approach & No. of pts. $\begin{array}{l}\text { Patient character- } \\
\text { istics }\end{array}$ & Reported FU (months) \\
\hline $\begin{array}{llllll}\text { Zhou et al. [33] } \\
\text { Xu, J et al. [34] }\end{array}$ & 2012 China & Abstract poster & Robotic & 44 & - & Unclear \\
& & & Abstract poster & Laparoscopic 1 & $\begin{array}{l}\text { 68-Year-old man, } \\
\text { BC type IIIa, no } \\
\text { vascular involve- } \\
\text { ment }\end{array}$ \\
\hline
\end{tabular}

$F U$ follow-up, $L F U$ lost to follow-up, $B C$ Bismuth-Corlette

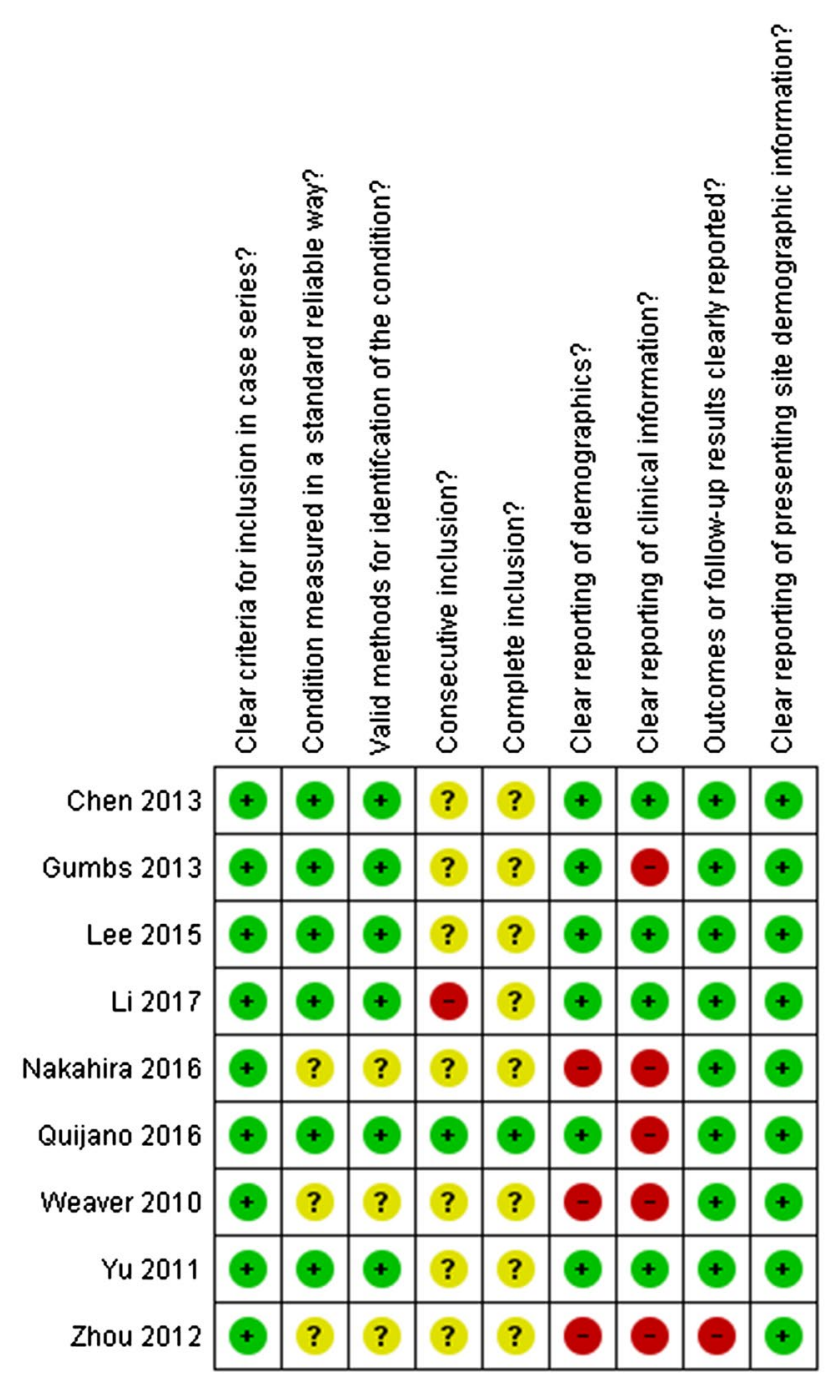

Fig. 2 Risk of bias case series (JBI)

hemihepatectomies, 8 right hemihepatectomies, 10 extended right hemihepatectomies, and 2 extended left hemihepatectomies). In the remaining 44 patients, the external bile duct resection was combined with caudate lobe resection or minor hepatectomy.

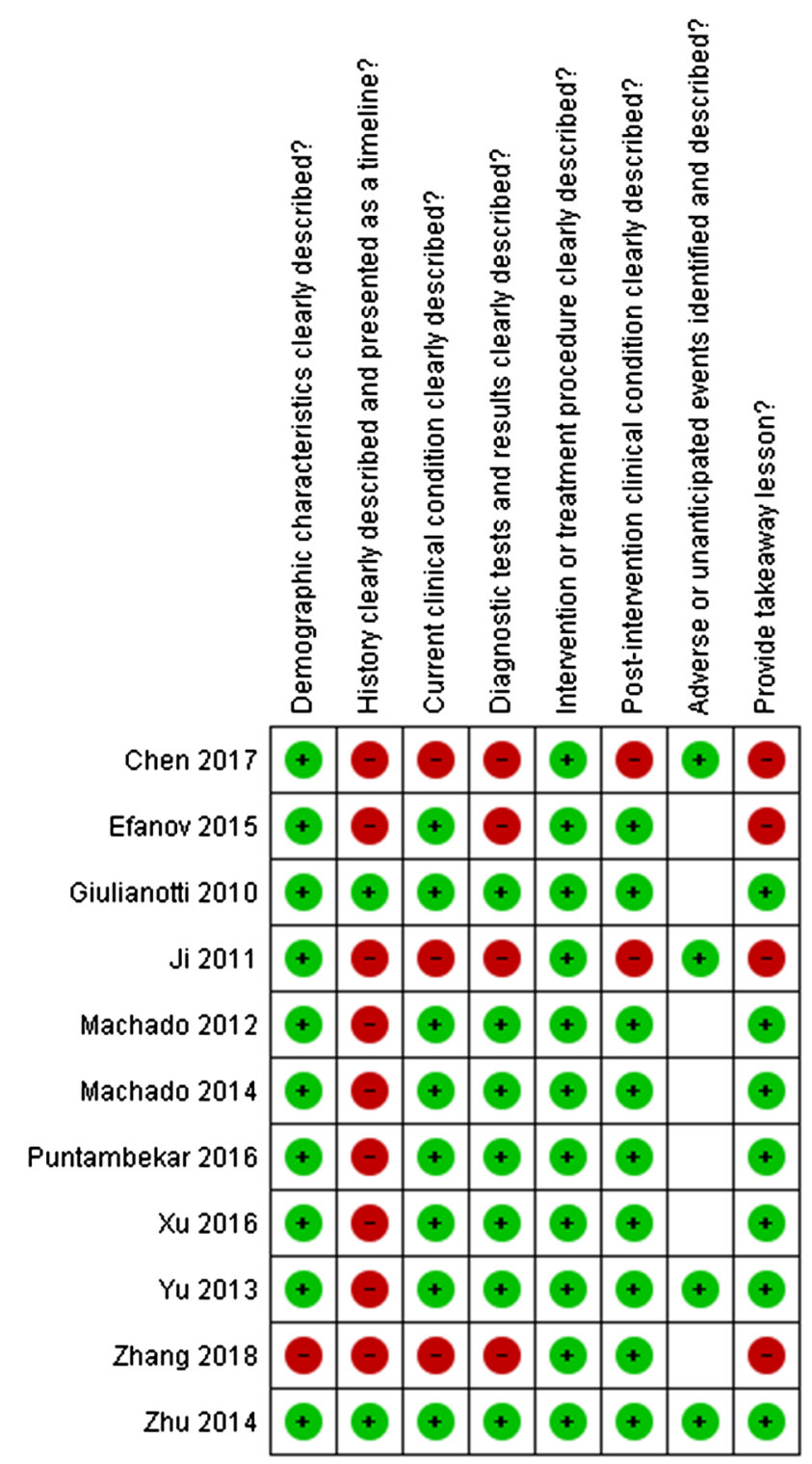

Fig. 3 Risk of bias case reports (JBI) 


\section{Operative outcomes}

Due to high heterogeneity across studies and major differences in population and procedures, the operative time, hospital stay, and blood loss varied widely. Generally, operative time of robotic procedures was longer compared to laparoscopic procedures. Across all included procedures average operation time was $381 \mathrm{~min}$ (range 205-1010 min) and average blood loss was $398 \mathrm{ml}$ (range 43-2169 ml). Overall, the conversion rate to open surgery was $4.9 \%$ (7/142). The shortest reported hospital stay was 3 days, while the longest post-operative admission was reported to be 58 days. The average hospital stay across all studies was 10.8 days. $\mathrm{Xu}$ et al. [15] reported that the robotic procedures showed a longer operative time, hospital stay and more blood loss compared to open surgery (703 vs $475 \mathrm{~min}, 16$ vs. 14 days, 1360 vs $1014 \mathrm{ml}$, respectively). Differences in hospital costs were only described by $\mathrm{Xu}$ et al, showing significantly higher costs for the robotic approach compared to the open approach $(27,427 \pm 21,316$ versus $15,282 \pm 5957$ dollar, respectively).

The pooled post-operative morbidity rate was $30 / 126$ (23.8\%) (see Table 2). Although the follow-up duration was unclear in one included study conducted by Zhou et al. [33], their reported morbidity of 8/44 (18.2\%) and mortality of $1 / 44(2.7 \%)$ were included in the pooled morbidity and mortality because data on post-operative outcomes were scarce. The most frequently reported complication was bile leakage, overall 15 times described. Additionally, one posthepatectomy liver failure, four peritoneal/pleural effusions, two thromboses (portal vein and lower extremities), one hemorrhage, and one intra-abdominal fluid collection were described. Overall 90-day mortality was 3.2\% (4/126), calculated with data from 13 studies with mortality ranging between 0 and $22 \%$. The only comparative study showed a significant difference in morbidity between the open and robotic approach in favor of the open approach: 9/10 (90\%) patients undergoing robotic surgery experienced complications compared to $16 / 32(50 \%)$ in the group undergoing open surgery. Mortality did not differ significantly between open $(6.3 \%)$ and robotic surgery (10\%) [15]. Morbidity and mortality per study are listed in Table 2 . Resection margins were reported in 57 cases, of which 46 R0-resection (79.3\%), seven R1-resection, and two R2-resections.

\section{Discussion}

In this first systematic review on MIS in patients with PHC, we found that this field is still in its infancy. A total of 142 laparoscopic and robot-assisted procedures in patients with PHC were reported. Case series and case reports included in this study show that laparoscopic and robotic external bile duct resection combined with (hemi)-hepatectomy is technically feasible in highly selected patients with PHC in experienced hands. However, results from the only comparative study that was identified appear to be in favor of the open approach.

The only comparative study, by $\mathrm{Xu}$ et al, included in this systematic review showed that MIS is inferior to the open approach in patients with PHC in terms of operative time, blood loss, morbidity and mortality [15]. Clearly, a learning curve effect cannot be excluded. All other included studies were non-comparative and small, retrospective case series or case reports. This introduces a high risk of selection and publication bias. For example, combining results from all included case reports and case series showed a conversion rate of 5\% (7/142). Nevertheless, in laparoscopic major liver resection, literature shows a range of conversion rate between 9 and 42\% [36] and even in laparoscopic cholecystectomy the conversion rate remains between 5 and 10\% [37]. The conversion rate of $4.9 \%$ seems thus extremely low. Furthermore, the total of 4 deaths and 30 complications among 126 patients suggests an overall 90 -day mortality of $3 \%$ and a post-operative morbidity rate of $24 \%$. Mortality and morbidity of open surgery in patients with $\mathrm{PCH}$ are infamously high and reported up to 18 and $68 \%$, respectively [2, 4]. Looking at duration of hospitalization, the average hospital stay for patients undergoing open surgery for PHC varies between 16 [38] and 23 days [39]. Comparing this with the average hospital stay for MIS in this review of 10.8 days, it may appear that MIS results in a shorter hospital stay. These comparisons with literature suggest a benefit of MIS compared to open surgery, but should be interpreted with extreme caution: these preliminary results may not be truly representative of current practice and are very likely to be influenced by strict patient selection and may represent only the favorable outcomes. Furthermore, all included studies derived from high-volume HPB units with surgeons experienced in minimally invasive HPB surgery. Therefore, results cannot be widely reproduced and should limit the use of MIS for this specific patient population to only those experienced centers.

R0 resection was achieved in almost $80 \%$ of patients. A large series consisting of 331 open resections of PHC shows that only in $59 \%$ of the cases R0 resection could be achieved [40]. This most likely confirms the presence of selection bias. On the other hand, the previously described meta-analysis on laparoscopic hepatectomies showed no significant differences in resection margins either [10]. Due to a lack of long-term follow-up, the effect of MIS on oncological outcomes remains uncertain.

One of the major limitations of this study was the abovedescribed substantial risk of bias. Because of this significant risk of selection and publication bias, results presented 


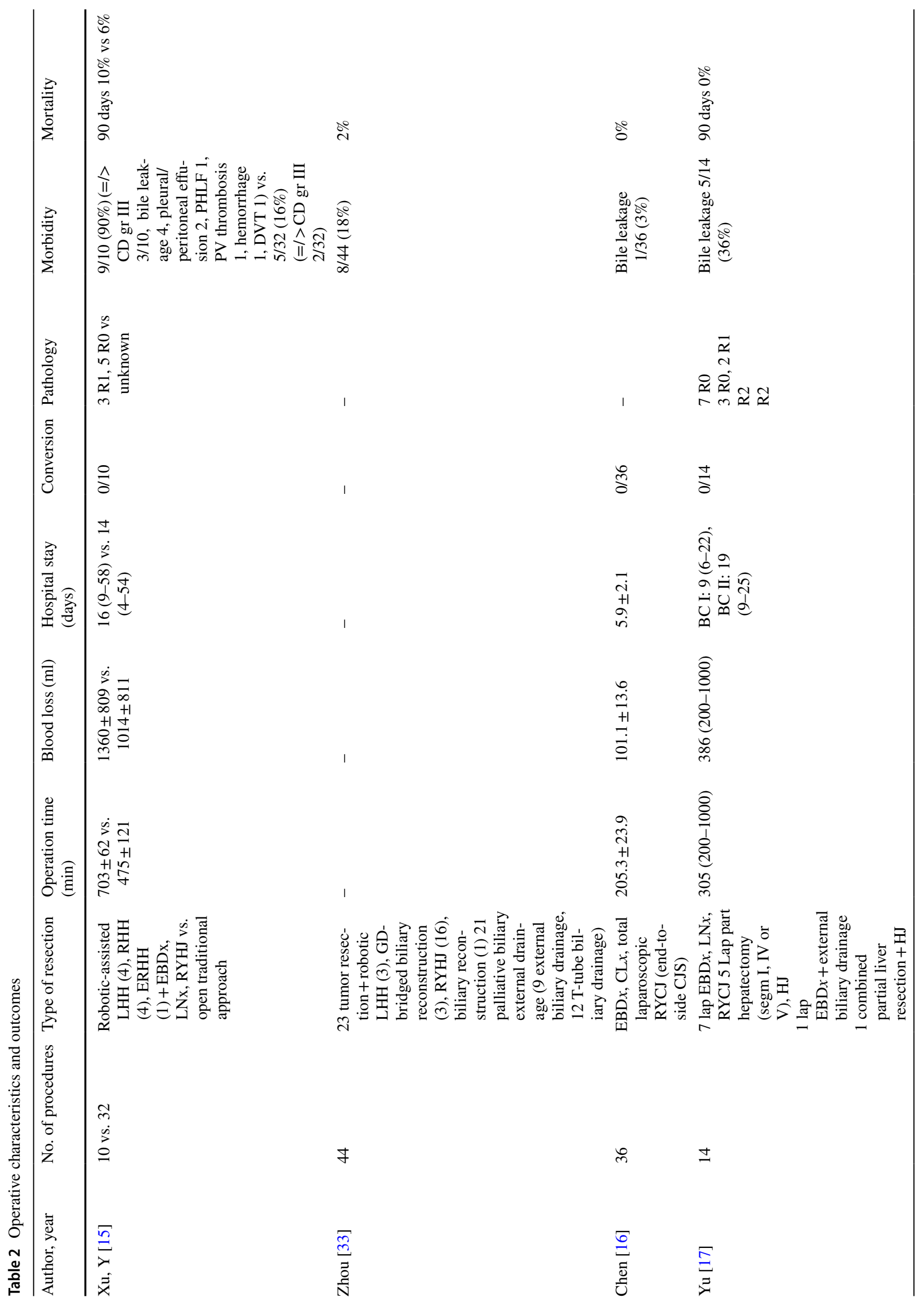




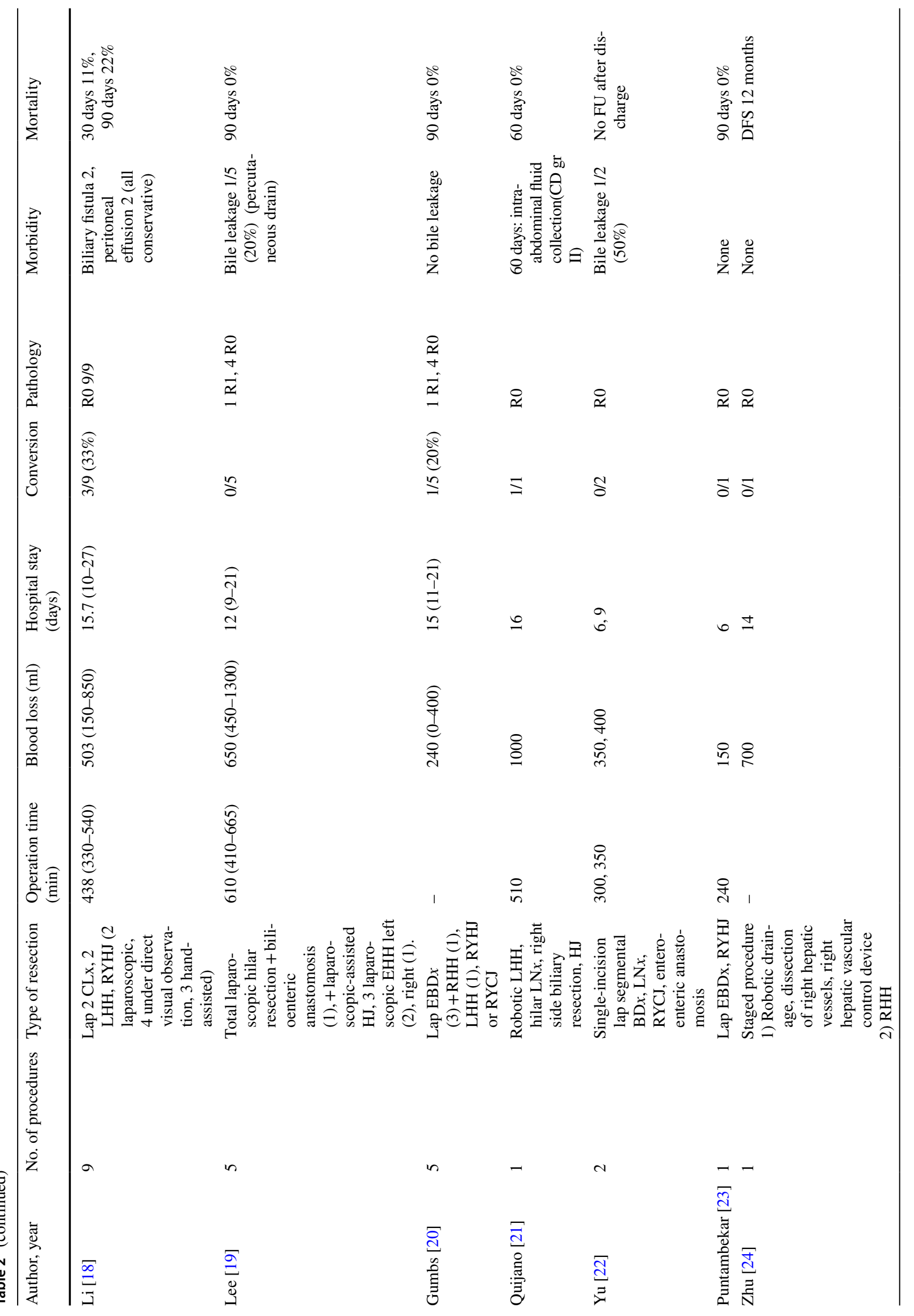




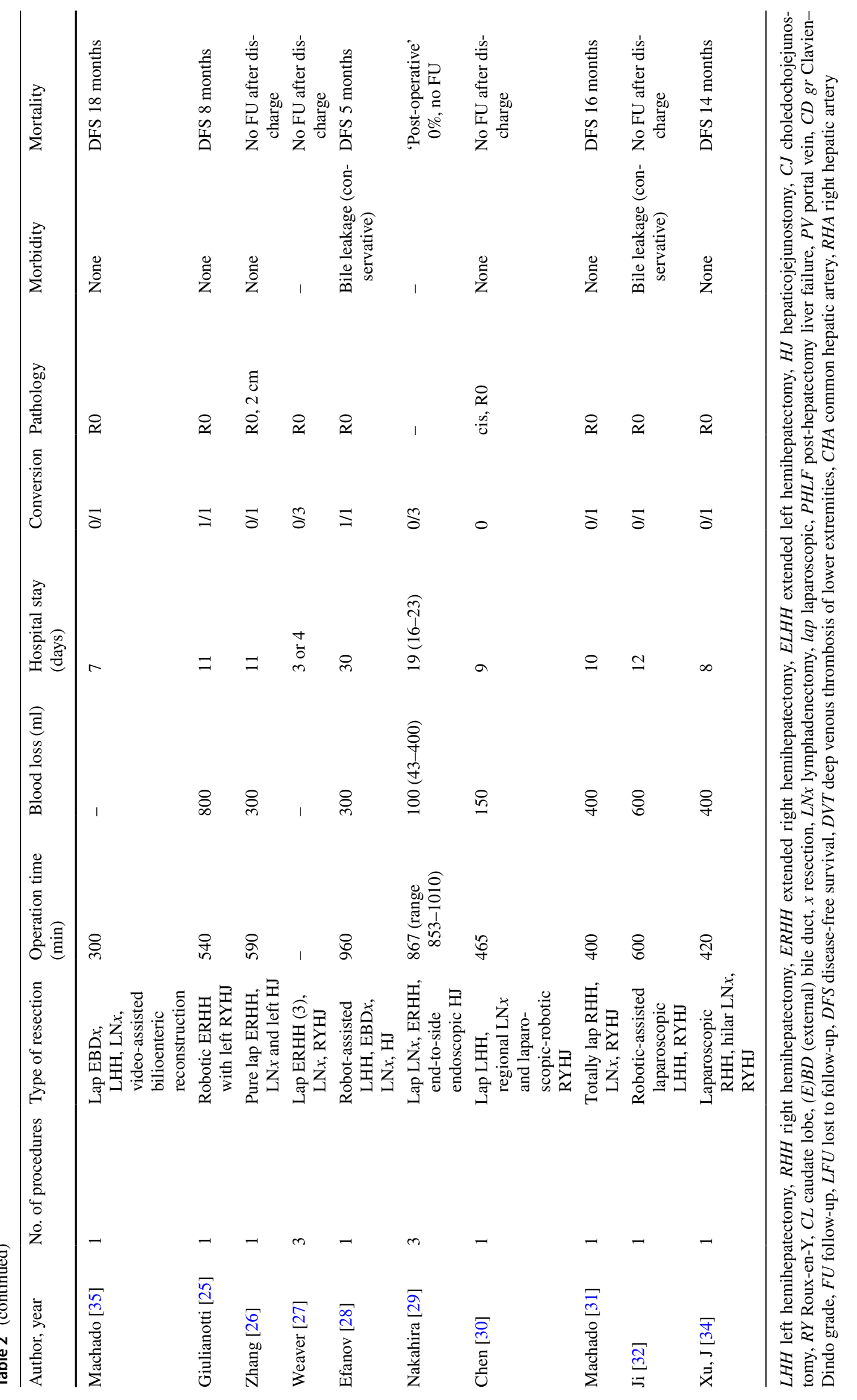


in this review based on these case series and case reports have a potential bias towards a good result. Also, all studies included in this systematic review were retrospective, small and generally of poor quality. Another limitation was the high heterogeneity among patient cohort and procedures.

This systematic review identified preliminary results from low-quality studies from highly experienced centers on MIS in PHC. It remains to be seen if the inherent benefits of MIS are applicable in this highly complex patient population and further research should focus on a safe implementation. To secure a safe and transparent implementation of MIS in PHC, patients should only be treated within prospective studies in highly selected centers.

Funding No funding was received for this study.

\section{Compliance with ethical standards}

Conflict of interest LC. Franken declares that she has no conflict of interest, M.J. van der Poel declares that he has no conflict of interest, A.E.J. Latenstein declares that she has no conflict of interest, M.J.W. Zwart declares that he has no conflict of interest, E. Roos declares that she has no conflict of interest, O.R.C. Busch declares that he has no conflict of interest, M.G. Besselink declares that he has no conflict of interest, T.M. van Gulik declares that he has no conflict of interest.

Ethical approval This article does not contain any studies with human participants performed by any of the authors.

Open Access This article is distributed under the terms of the Creative Commons Attribution 4.0 International License (http://creativeco mmons.org/licenses/by/4.0/), which permits unrestricted use, distribution, and reproduction in any medium, provided you give appropriate credit to the original author(s) and the source, provide a link to the Creative Commons license, and indicate if changes were made.

\section{References}

1. Regimbeau JM, Fuks D, Le Treut YP, Bachellier P, Belghiti J, Boudjema K et al (2011) Surgery for hilar cholangiocarcinoma: a multi-institutional update on practice and outcome by the AFC-HC study group. J Gastrointest Surg 15(3):480-488

2. Olthof PB, Coelen RJ, Wiggers JK, Besselink MG, Busch OR, van Gulik TM (2016) External biliary drainage following major liver resection for perihilar cholangiocarcinoma: impact on development of liver failure and biliary leakage. HPB 18(4):348-353

3. Nagino M, Ebata T, Yokoyama Y, Igami T, Sugawara G, Takahashi Y et al (2013) Evolution of surgical treatment for perihilar cholangiocarcinoma: a single-center 34-year review of 574 consecutive resections. Ann Surg 258(1):129-140

4. Farges O, Regimbeau JM, Fuks D, Le Treut YP, Cherqui D, Bachellier P et al (2013) Multicentre European study of preoperative biliary drainage for hilar cholangiocarcinoma. Br J Surg 100(2):274-283

5. Coelen RJ, Olthof PB, van Dieren S, Besselink MG, Busch OR, van Gulik TM (2016) External validation of the estimation of physiologic ability and surgical stress (E-PASS) risk model to predict operative risk in perihilar cholangiocarcinoma. JAMA Surg 151(12):1132-1138

6. Popescu I, Dumitrascu T (2014) Curative-intent surgery for hilar cholangiocarcinoma: prognostic factors for clinical decision making. Langenbeck's Arch Surg 399(6):693-705

7. van Gulik TM, Kloek JJ, Ruys AT, Busch OR, van Tienhoven GJ, Lameris JS et al (2011) Multidisciplinary management of hilar cholangiocarcinoma (Klatskin tumor): extended resection is associated with improved survival. Euro J Surg Oncol 37(1):65-71

8. Nishio H, Nagino M, Nimura Y (2005) Surgical management of hilar cholangiocarcinoma: the Nagoya experience. HPB 7(4):259-262

9. Evers L, Bouvy N, Branje D, Peeters A (2017) Single-incision laparoscopic cholecystectomy versus conventional four-port laparoscopic cholecystectomy: a systematic review and metaanalysis. Surg Endosc 31(9):3437-3448

10. de Rooij T, Lu MZ, Steen MW, Gerhards MF, Dijkgraaf MG, Busch OR et al (2016) Minimally invasive versus open pancreatoduodenectomy: systematic review and meta-analysis of comparative cohort and registry studies. Ann Surg 264(2):257-267

11. Ciria R, Cherqui D, Geller DA, Briceno J, Wakabayashi G (2016) Comparative short-term benefits of laparoscopic liver resection: 9000 cases and climbing. Ann Surg 263(4):761-777

12. Okunrintemi V, Gani F, Pawlik TM (2016) National trends in postoperative outcomes and cost comparing minimally invasive versus open liver and pancreatic surgery. J Gastrointest Surg 20(11):1836-1843

13. Fretland AA, Dagenborg VJ, Bjornelv GMW, Kazaryan AM, Kristiansen R, Fagerland MW et al (2018) Laparoscopic versus open resection for colorectal liver metastases: the OSLOCOMET randomized controlled trial. Ann Surg 267(2):199-207

14. Levi Sandri GB, Spoletini G, Masciana G, Colasanti M, Lepiane P, Vennarecci G et al (2017) The role of minimally invasive surgery in the treatment of cholangiocarcinoma. Euro J Surg Oncol 43(9):1617-1621

15. Xu Y, Wang H, Ji W, Tang M, Li H, Leng J et al (2016) Robotic radical resection for hilar cholangiocarcinoma: perioperative and long-term outcomes of an initial series. Surg Endosc 30(7):3060-3070

16. Chen D, Zhu A, Zhang Z (2013) Total laparoscopic roux-en-Y cholangiojejunostomy for the treatment of biliary disease. JSLS 17(2):178-187

17. Yu H, Wu SD, Chen DX, Zhu G (2011) Laparoscopic resection of Bismuth type I and II hilar cholangiocarcinoma: an audit of 14 cases from two institutions. Dig Surg 28(1):44-49

18. Li J, Zhao L, Zhang J, Li Z, Li A, Wei Y et al (2017) Application of the laparoscopic technique in perihilar cholangiocarcinoma surgery. Int J Surg (Lond, Engl) 44:104-109

19. Lee W, Han HS, Yoon YS, Cho JY, Choi Y, Shin HK et al (2015) Laparoscopic resection of hilar cholangiocarcinoma. Ann Surg Treat Res 89(4):228-232

20. Gumbs AA, Jarufe N, Gayet B (2013) Minimally invasive approaches to extrapancreatic cholangiocarcinoma. Surg Endosc 27(2):406-414

21. Quijano Y, Vicente E, Ielpo B, Duran H, Diaz E, Fabra I et al (2016) Robotic liver surgery: early experience from a single surgical center. Surg Laparosc Endosc Percutaneous Tech 26(1):66-71

22. Yu H, Wu SD, Tian Y, Su Y, Li YN (2013) Single-incision laparoscopic resection of bismuth I hilar cholangiocarcinoma. Surg Innov 20(3):209-213

23. Puntambekar S, Sharma V, Kumar S, Mitkare S, Joshi G, Parikh H (2016) Laparoscopic management of hilar cholangiocarcinoma: a case report. Indian J Surg 78(1):57-59 
24. Zhu Z, Liu Q, Chen J, Duan W, Dong M, Mu P et al (2014) Robotic surgery twice performed in the treatment of hilar cholangiocarcinoma with deep jaundice: delayed right hemihepatectomy following the right-hepatic vascular control. Surg Laparosc Endosc Percutaneous Tech 24(5):e184-e190

25. Giulianotti PC, Sbrana F, Bianco FM, Addeo P (2010) Robotassisted laparoscopic extended right hepatectomy with biliary reconstruction. J Laparoendosc Adv Surg Tech Part A 20(2):159-163

26. Zhang CW, Liu J, Hong DF, Wang ZF, Hu ZM, Huang DS et al (2018) Pure laparoscopic radical resection for type IIIa hilar cholangiocarcinoma. Surg Endosc 32(3):1581-1582

27. Weaver J, Paul E, Lin E, Sarmiento J (2010) Three cases of laparoscopic hilar cholangiocarcinoma resection with hepaticojejunal reconstruction and portal lymph node dissection. Hpb 12:121-122

28. Efanov M, Alikhanov R, Cvircun V, Kazakov I, Melekhina O, Vankovich A et al (2015) Robotic-assisted radical resection for hilar cholangiocarcinoma, first russian experience. Hpb 17:276

29. Nakahira S, Takeda Y, Katsura Y, Irei T, Inoue M, Odagiri K et al (2016) Laparoscopic extended right hepatectomy with biliary reconstruction for hilar cholangiocarcinoma. Hpb 18:e798

30. Chen KH, Siow TF, Chio UC, Chen YD, Chang YJ, Lin TC et al (2017) Robotic assisted resection of hilar cholangiocarcinoma. Surg Endosc Other Int Tech 31(2 Supplement 1):S473

31. Machado MA, Makdissi FF, Surjan RC (2014) Totally laparoscopic right hepatectomy with roux-en-y hepaticojejunostomy for hilar cholangiocarcinoma. Hpb 16:707

32. Ji (2011) Robotic-Assisted laparoscopic radical resection with major hepatectomy for hilar Cholangiocarcinoma. HPB 13(suppl 3): 12

33. Zhou N (2012) Analysis of results of 44 cases of hilar cholangiocarcinoma after da VINCI surgery. Hpb 14:450
34. Xu J, Min J, Chen Y (2016) Totally laparoscopic right hepatectomy, portal lymphadenectomy, and hepaticojejunostomy for hilar cholangiocarcinoma: a case report. Hpb 18:e467

35. Machado MA, Makdissi FF, Surjan RC, Mochizuki M (2012) Laparoscopic resection of hilar cholangiocarcinoma. J Laparoendosc Adv Surg Tech Part A 22(10):954-956

36. Kasai M, Cipriani F, Gayet B, Aldrighetti L, Ratti F, Sarmiento JM et al (2018) Laparoscopic versus open major hepatectomy: a systematic review and meta-analysis of individual patient data. Surgery 163(5):985-995

37. Livingston EH, Rege RV (2004) A nationwide study of conversion from laparoscopic to open cholecystectomy. Am J Surg 188(3):205-211

38. Dumitrascu T, Brasoveanu V, Stroescu C, Ionescu M, Popescu I (2016) Major hepatectomies for perihilar cholangiocarcinoma: predictors for clinically relevant postoperative complications using the International Study Group of Liver Surgery definitions. Asian J Surg 39(2):81-89

39. Lillemoe KD (2001) Klatskin tumors. In: Holzheimer RG, Mannick JA (eds) Surgical treatment: evidence-based and problemoriented. Zuckschwerdt, Munich

40. Regimbeau JM, Fuks D, Pessaux P, Bachellier P, Chatelain D, Diouf $\mathrm{M}$ et al (2015) Tumour size over $3 \mathrm{~cm}$ predicts poor shortterm outcomes after major liver resection for hilar cholangiocarcinoma By the HC-AFC-2009 group. HPB 17(1):79-86

Publisher's Note Springer Nature remains neutral with regard to jurisdictional claims in published maps and institutional affiliations. 